\title{
MODELLING AND SIMULATIONS OF DYNAMICS OF THE LOW-FLOOR TRAMCAR WITH INDEPENDENTLY ROTATING WHEELS
}

The article is devoted to the analysis of numerical simulation results of the tramcar dynamics. It presents the mathematical model of the one section of the low-floor tram with the bogie with independently rotating wheels. The simulations were performed according to different scenarios, connected with the track geometry, which seem to be dangerous for the tram behaviour e.g.: curving, gauge narrowing, track buckling, etc. Special attention was paid to wheel lateral displacement and forces occurring in wheel-rail contact. The simulation results reveal characteristic features of such an unconventional system of the tram, which can often demonstrate dynamics considered worse than in the conventional case of the tramcar.

Keywords: Low-floor tramcar, independently rotating wheels.

\section{Introduction}

Currently, the demand of the urban transport providers on the modern tramcars leads designers to the new point of view of the tramcar construction. However, the realisation of the goal which is a constant improvement of the passengers comfort cannot be fulfilled further. The reason is a construction of the bogies, which makes the introduction of $100 \%$ low floor impossible. The researchers adjust to new design requirements and analyse the unconventional wheelsets with independently rotating wheels.

Present research paper aims at development of the model of unconventional bogie in the tramcar section. As the characteristic features of the dynamics of such wheelsets are still not well known, several simulations were performed in order to recognize the behaviour of the system. The results of simulations were analysed and general conclusions derived.

Studies on the concepts of wheelsets with independently rotating wheels have started in the half of the last century. These studies have concentrated generally on the steering strategies of running gear that could overcome the drawbacks of IRW bogie design. Positions [ 1 - 3] deal with the active control of the wheelsets and survey various possibilities of its control. Goodall in [4] presents experimental approach to torque control of IRW wheelsets. Paper [5] deals with the comparison of mathematical modelling of both conventional and unconventional bogies. The earlier works as [6] which concern mathematical modelling of unconventional bogies is also worth mentioning. Self-steering ability of wheelsets with independently rotating wheels, known as Einzelrad - Einzelfahrwerk, which uses gravity stiffness was proposed in [7] and [8]. Papers [9] and [10] concern the subject of dynamics of tramway with wheelsets equipped with IRW. Paper [9] deals with the linear model of a bogie with independently rotating wheels and paper [10] uses commercial software package to solve equations of motion. The problem of low floor tram dynamics was also the subject of authors' papers [11] and [12]. These articles discussed problem of stability of different types of low floor tram bogies.

\section{Model}

The three dimensional model of tramcar dynamics was considered in all cases of simulations. One section of the tramcar has 20 degrees of freedom and consists of four rigid bodies which are

- car body, which has 6 degrees of freedom,

- bogie frame body, which has 6 degrees of freedom,

- two wheelsets with independently rotating wheels which have 4 degrees of freedom each.

The section of the tramcar with marked degrees of freedom of car body is presented in Fig. 1 .

\footnotetext{
* Andrzej Chudzikiewicz, Magdalena Sowinska

Warsaw University of Technology, Faculty of Transport, Warsaw, Poland

E-mail: ach1@wt.pw.edu.pl
} 


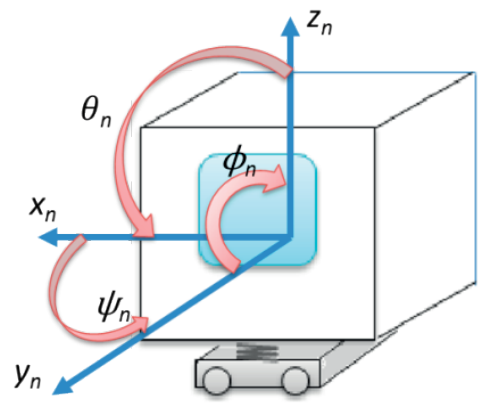

Fig. 1 Tramcar section scheme with degrees of freedom of the car body

Degrees of freedom of the bogie frame are analogical to the car body degrees of freedom. The unconventional wheelset with independently rotating wheels has a cranked axle which allows lowering the floor in the whole tramcar inner space. Such a wheelset has the wheels mounted on the common axle with the use of bearing system which enables independent rotation of wheels. In this case, the wheelset has 4 degrees of freedom as it is visible in Fig. 2a. The analysis of dynamics of the wheelset is limited to the motion in a horizontal plane. The whole model of the bogie has 14 degrees of freedom and it is symmetric with respect to $\mathrm{x}$ axis as captured in Fig. $2 \mathrm{~b}$.

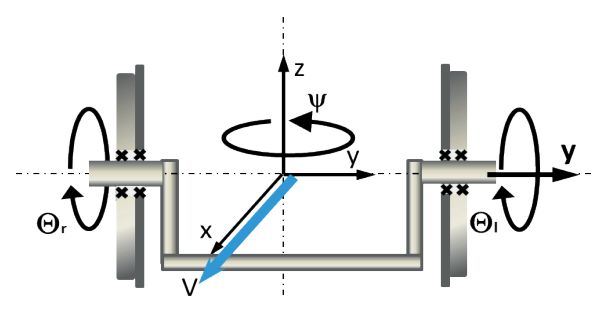

a)

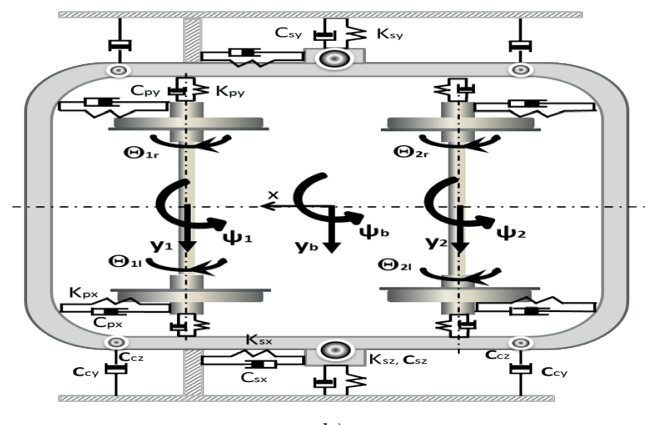

b)

Fig. 2 a) the wheelset model

b) the bogie model with elastic-damping elements marked

Bodies are connected with the elastic and damping elements which have linear characteristics. Inertial parameters as well as stiffness and damping correspond to the construction of the low floor tramcar which has been introduced lately to the exploitation in the Warsaw city transport. During simulation studies we assume that the tramcar is moderately loaded with passengers.

The vehicle's motion is investigated in the non-inertial frame connected with the centreline of a track. The Fastsim procedure was involved in the numerical calculations. However, the procedure had to be modified in terms of creepages formulas, because of the free rolling of the wheels. For that reason, the longitudinal creepage was assumed zero. Material parameters taken to the procedure match parameters of steel $900 \mathrm{~A}$ according to PN - EN 13674-1. Rail profiles were typical grooved tramway track rails Ri60.

\section{Simulation study}

The track's sections where the simulation research was conducted were considered potentially dangerous for railways traffic according to [13].

Figure 3 presents three different track geometries assumed for the simulations.

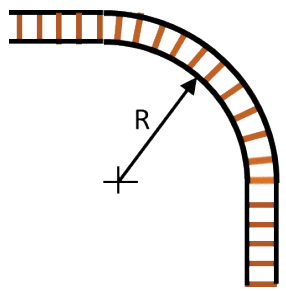

a)

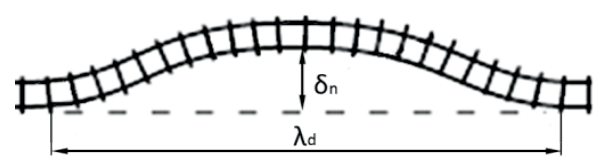

b)

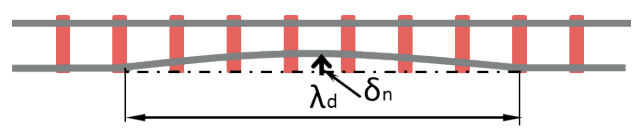

c)

Fig. 3 Tracks taken for the simulations:

a) steady curving b) buckled track

c) track with lateral misalignment

Figure $3 \mathrm{a}$ presents track in the steady curving case and it is modelled as a quarter of the circle with straight entrance and exit, Fig. 3b pictures buckled track modelled as half of the sinusoid of $50 \mathrm{~cm}$ amplitude and long $10 \mathrm{~m}$, and Fig. $3 \mathrm{c}$ a track with lateral sinusoidal misalignment of $1 \mathrm{~cm}$ and $2 \mathrm{~cm}$ amplitude of right rail long $5 \mathrm{~m}$. Simulations were performed according to different velocities and track parameters.

Figure 4 presents lateral displacement of the wheelset's centre of mass during the ride on the curve (Fig. 3a) with velocity equal 


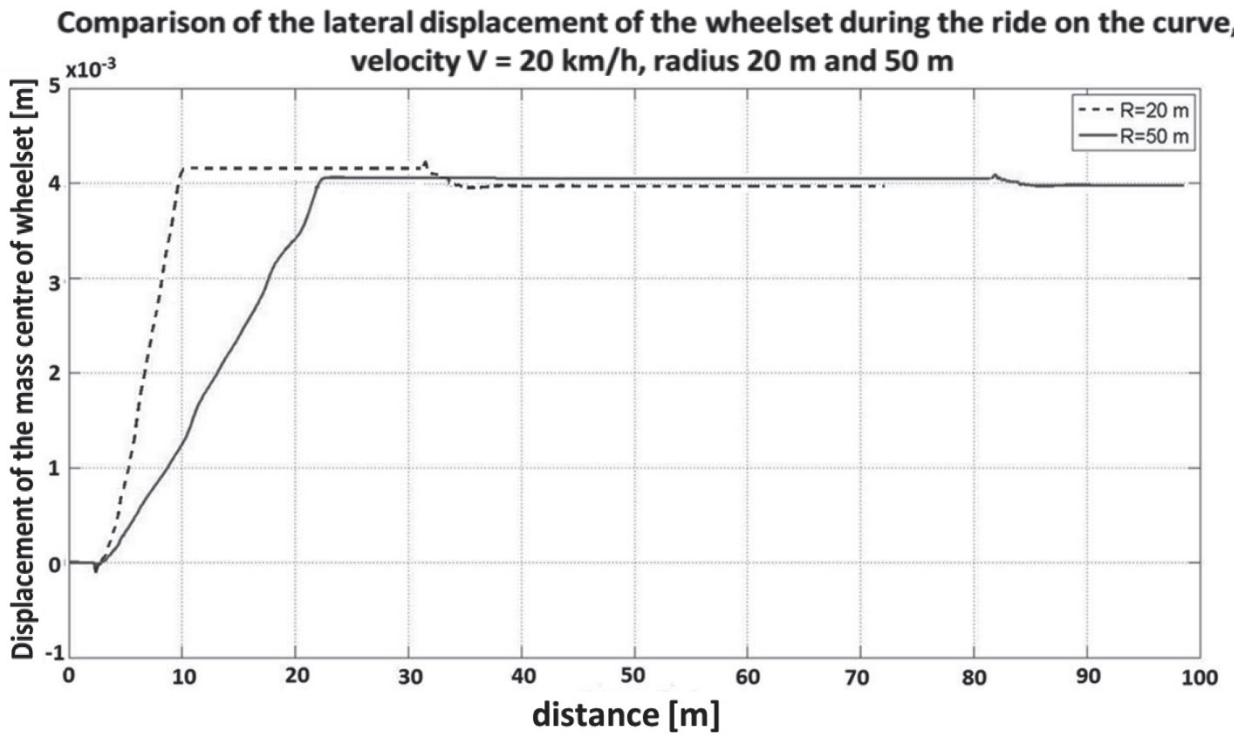

Fig. 4 Lateral displacement of the wheelset during the steady curving; 20 and $50 \mathrm{~m}$ radius, $20 \mathrm{~km} / \mathrm{h}$

to $20 \mathrm{~km} / \mathrm{h}$. It compares two curves of different radii: 20 and $50 \mathrm{~m}$.

The wheelset displaces faster to the maximal position on the tighter curve than on the curve of $50 \mathrm{~m}$ radius. The maximal position means the position when the wheel flange is in contact with the rail. In both cases such situation occurs. After exiting the curve the wheelsets remain displaced. The centre of the wheelset mass does not return to the central position on the track. Figure 5 shows the yaw angle of the wheelset in the same case of the track scenario.
It is shown that wheelsets with independently rotating wheels have the ability of radial positioning, because the yaw angle stabilizes on the zero value during the ride on the curve. The comparison of wheelset lateral displacement on the curve of $50 \mathrm{~m}$ radius in two cases of velocity is shown in Fig. 6. It reveals features which are: slow climbing up to the flange, remaining of the flange in the constant contact with the rail and no self-centring ability.

Figure 7 presents the lateral forces in the area of the wheel-rail contact and rail during the ride with the velocity of $40 \mathrm{~km} / \mathrm{h}$ on

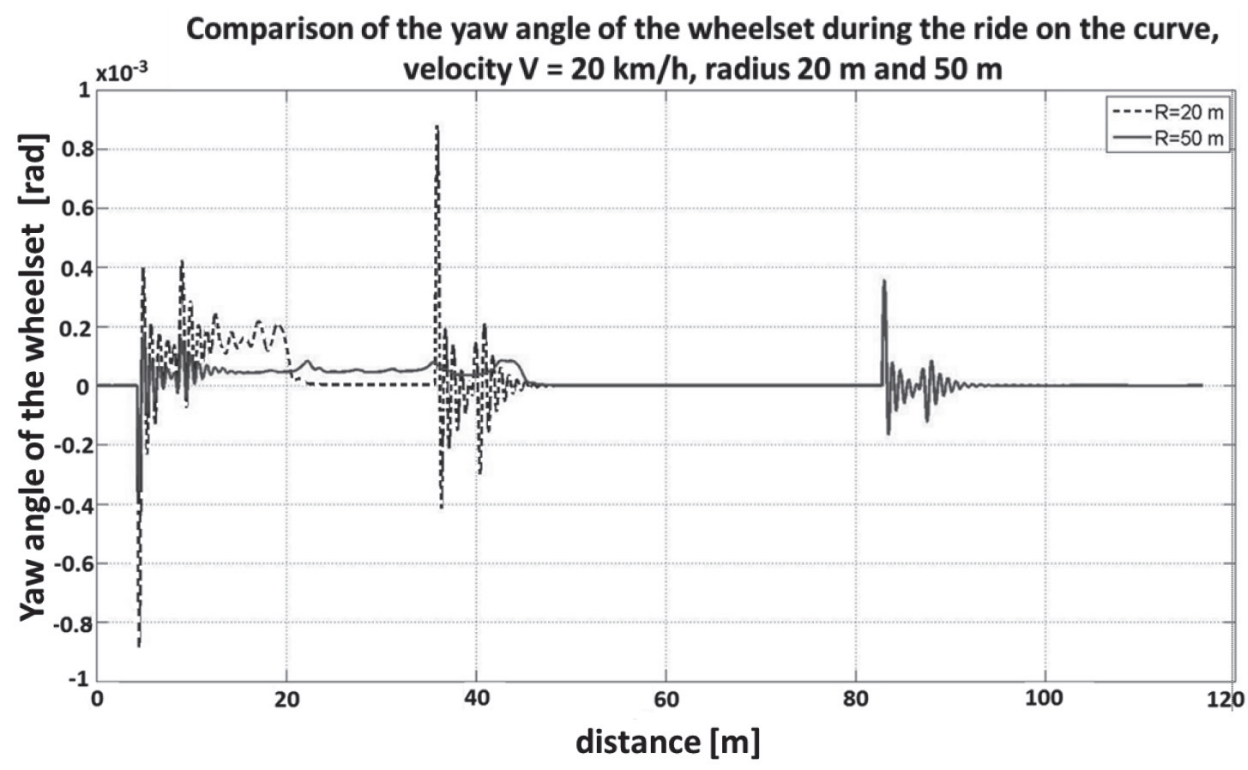

Fig. 5 Yaw angle of the wheelset during the steady curving; 20 and $50 \mathrm{~m}$ radius, $20 \mathrm{~km} / \mathrm{h}$ 


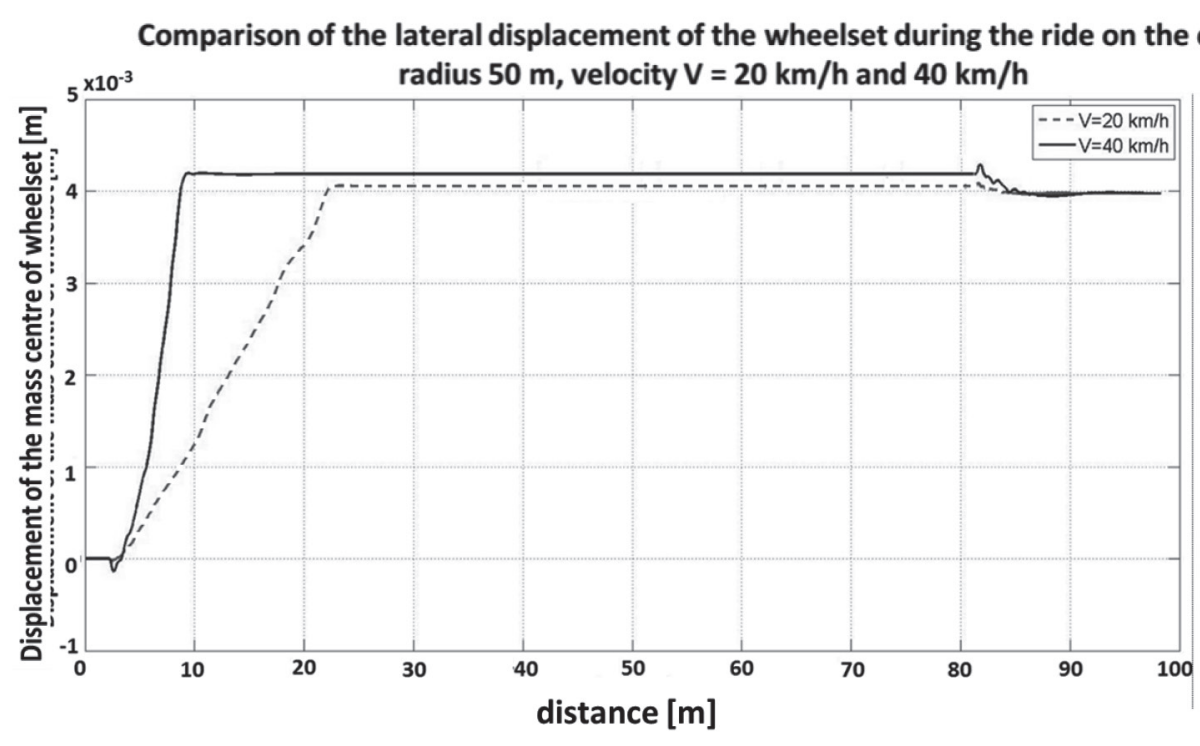

Fig. 6 Lateral displacement of the wheelset during the steady curving; $50 \mathrm{~m}$ radius, 20 and $40 \mathrm{~km} / \mathrm{h}$

the curve of $50 \mathrm{~m}$ radius. The graph compares the forces on the left and right side of the wheelset.

When the tramcar turns right on the curve, the lateral forces in the outer wheel area of contact are about $1.4 \mathrm{kN}$ and in the inner wheel area of contact are about $15 \mathrm{kN}$. The forces have an oscillating character around these values because of the flange-rail contact on the curve.

Next interesting features of such a wheelset appear in the simulation results of the ride on the buckled track. As it is visible in Fig. 8, the wheelsets perform distinctly different motion in the case of velocities equal to $40 \mathrm{~km} / \mathrm{h}$ and $60 \mathrm{~km} / \mathrm{h}$. When the velocity is $40 \mathrm{~km} / \mathrm{h}$, the wheelset has smaller displacements on the buckled section of the track than in $60 \mathrm{~km} / \mathrm{h}$ case. After exiting to the straight track the wheelset which rides with the velocity equal to $40 \mathrm{~km} / \mathrm{h}$ approaches shortly the centreline of the track and then returns to the previous position. When the velocity of ride is $60 \mathrm{~km} / \mathrm{h}$, the wheelset after exiting the buckled section passes the centreline and takes the maximum position on the other side of the track and does not return to the centre.

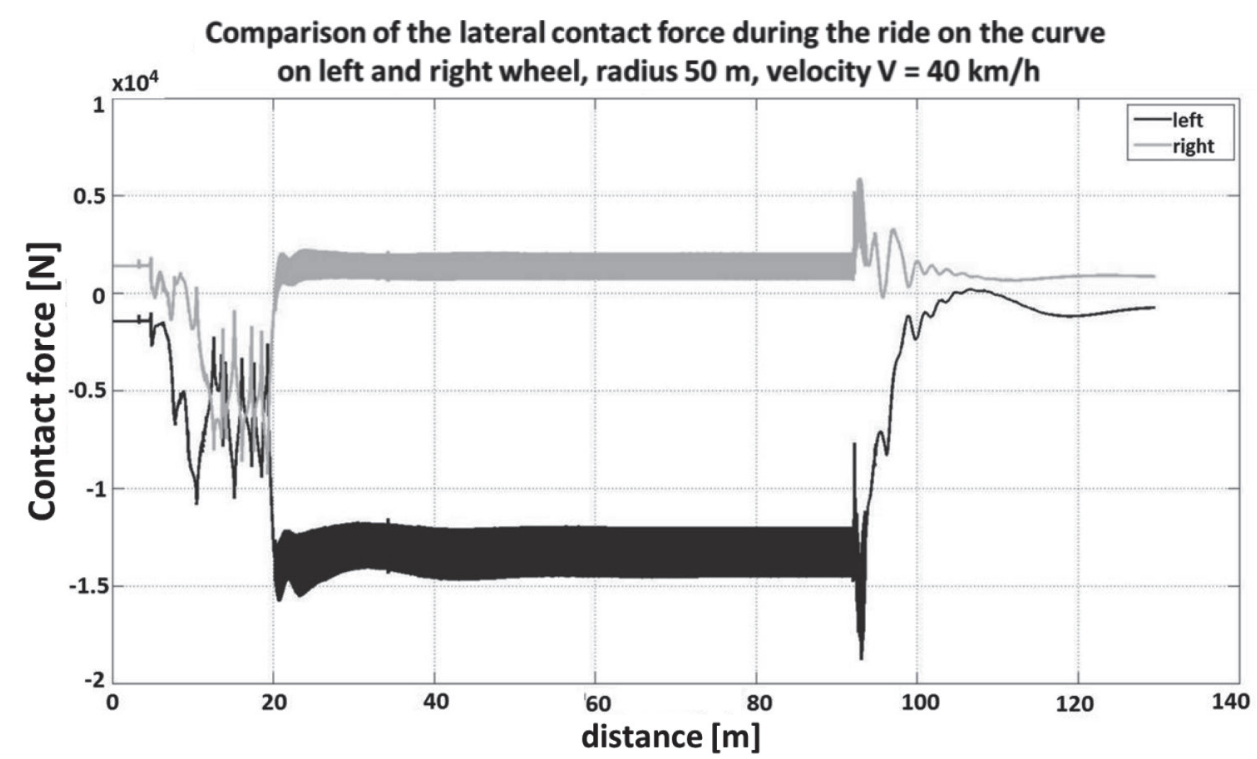

Fig. 7 Lateral contact forces on the left and right wheel during the steady curving; $50 \mathrm{~m}$ radius, $40 \mathrm{~km} / \mathrm{h}$ 




Fig. 8 Lateral displacement of the wheelset during the ride on the buckling; 40 and $60 \mathrm{~km} / \mathrm{h}$

Figures 9 and 10 present the lateral forces in the area of left and right wheel contact with the rail during the ride on the buckled track. When the velocity is equal to $40 \mathrm{~km} / \mathrm{h}$, the forces are approximately equal to $12 \mathrm{kN}$ on the entrance and exit from the buckled section.

Figure 10 pictures lateral forces in the area of wheel/rail contact in the case when the ride velocity is equal to $60 \mathrm{~km} / \mathrm{h}$.

The simulation results have shown that when the velocity increases to $60 \mathrm{~km} / \mathrm{h}$, the lateral forces values are about 5 times bigger than in the case when ride velocity is equal to $40 \mathrm{~km} / \mathrm{h}$.
Figure 11 presents lateral displacement of the wheelset on the last type of the track, which is a track with the lateral misalignment of one of the rails. This graph compares the response of the IRW wheelsets on the misalignment of different amplitude $-1 \mathrm{~cm}$ and $2 \mathrm{~cm}$. The ride velocity is constant and equal to $20 \mathrm{~km} / \mathrm{h}$. This scenario shows strong influence of misalignment on lateral motion of the wheelset. It seems that the bogie system nearly does not react on the $1 \mathrm{~cm}$ amplitude misalignment, which cannot be observed in the case of $2 \mathrm{~cm}$ amplitude. In this case, the lateral

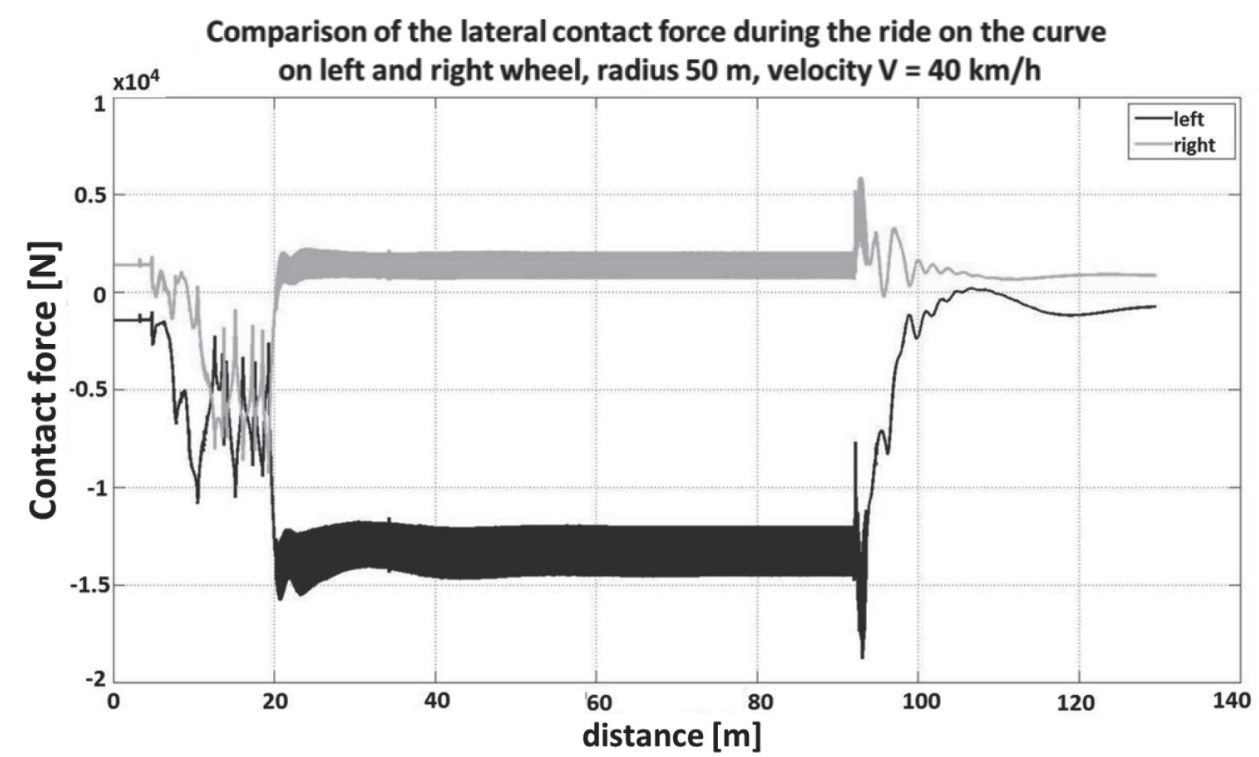

Fig. 9 Lateral contact forces on the left and right wheel during the ride on the buckling; $40 \mathrm{~km} / \mathrm{h}$ 


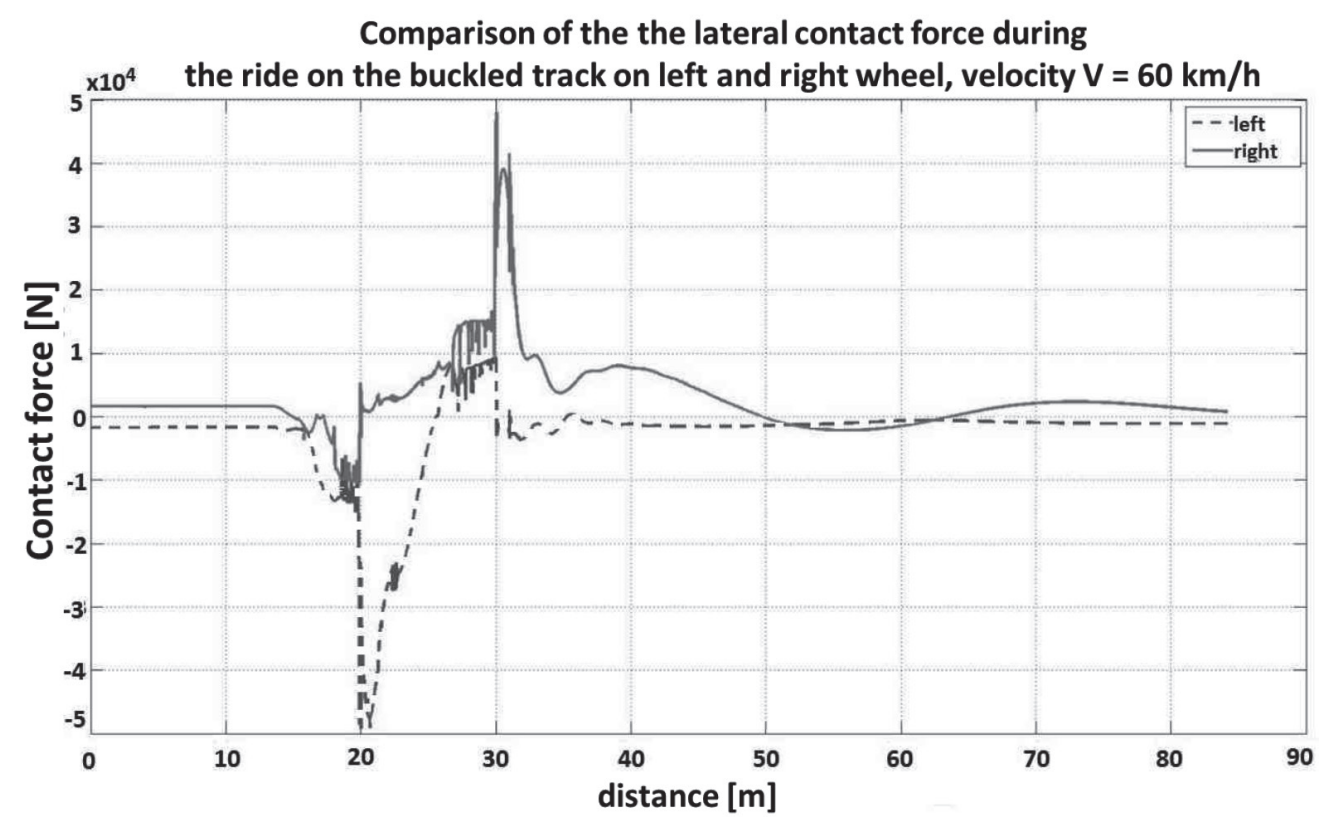

Fig. 10 Lateral contact forces on the left and right wheel during the ride on the buckling; $60 \mathrm{~km} / \mathrm{h}$

displacement of the wheelset increases till the flange-rail contact and afterwards decreases towards the centreline of the track.

Figure 12 depicts lateral forces in the area of wheel/rail contact in the case of $2 \mathrm{~cm}$ amplitude misalignment on the track.

Lateral forces in the case of $2 \mathrm{~cm}$ amplitude misalignment are equal to $47 \mathrm{kN}$ which is nearly the same value as in the case of 1 $\mathrm{cm}$ misalignment, however this force acts on the longer distance.

\section{Conclusion}

The paper presents examples of simulation results of the low floor tramcar motion performed according to different scenarios. Analysis of the results focuses on the lateral displacements of the wheelset's centre of mass, yaw angle of the wheelsets and lateral forces in the area of wheel and rail contact. The numerical model has shown that the new wheelset type requires a modified

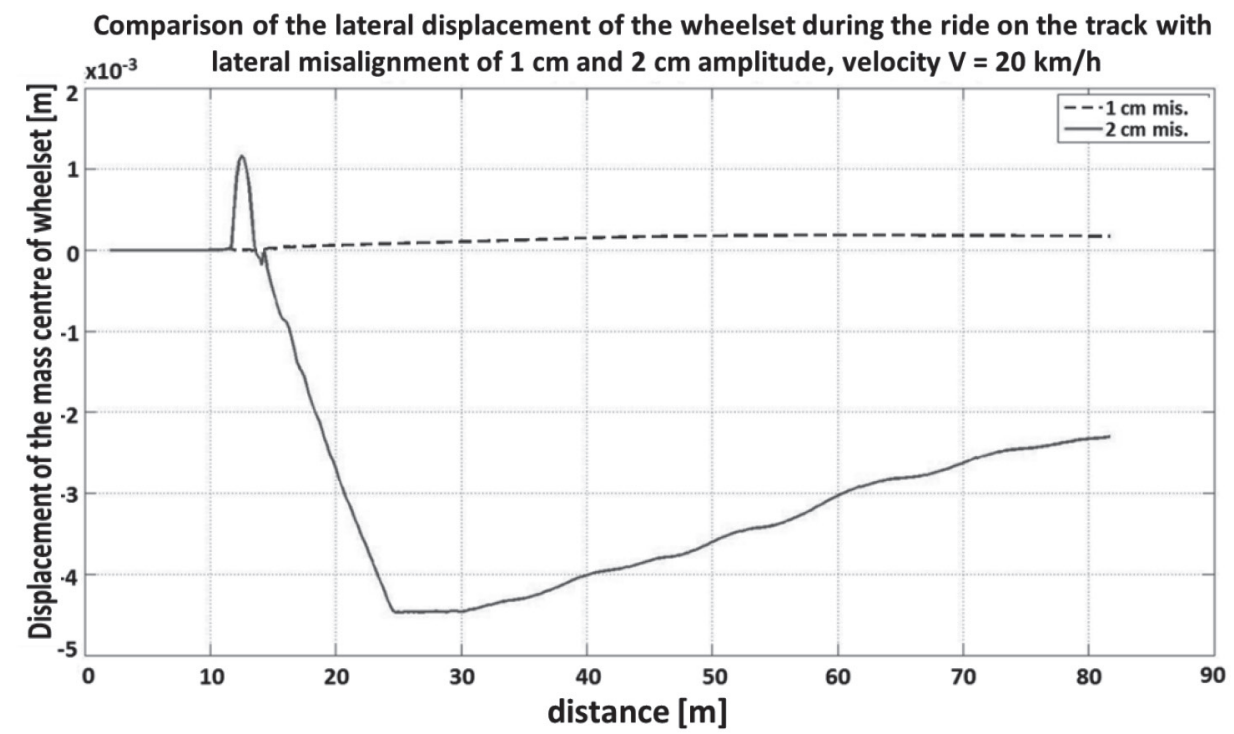

Fig. 11 Lateral displacement of the wheelset during the ride on the track with lateral misalignment; 1 and $2 \mathrm{~cm}$ amp., $20 \mathrm{~km} / \mathrm{h}$ 


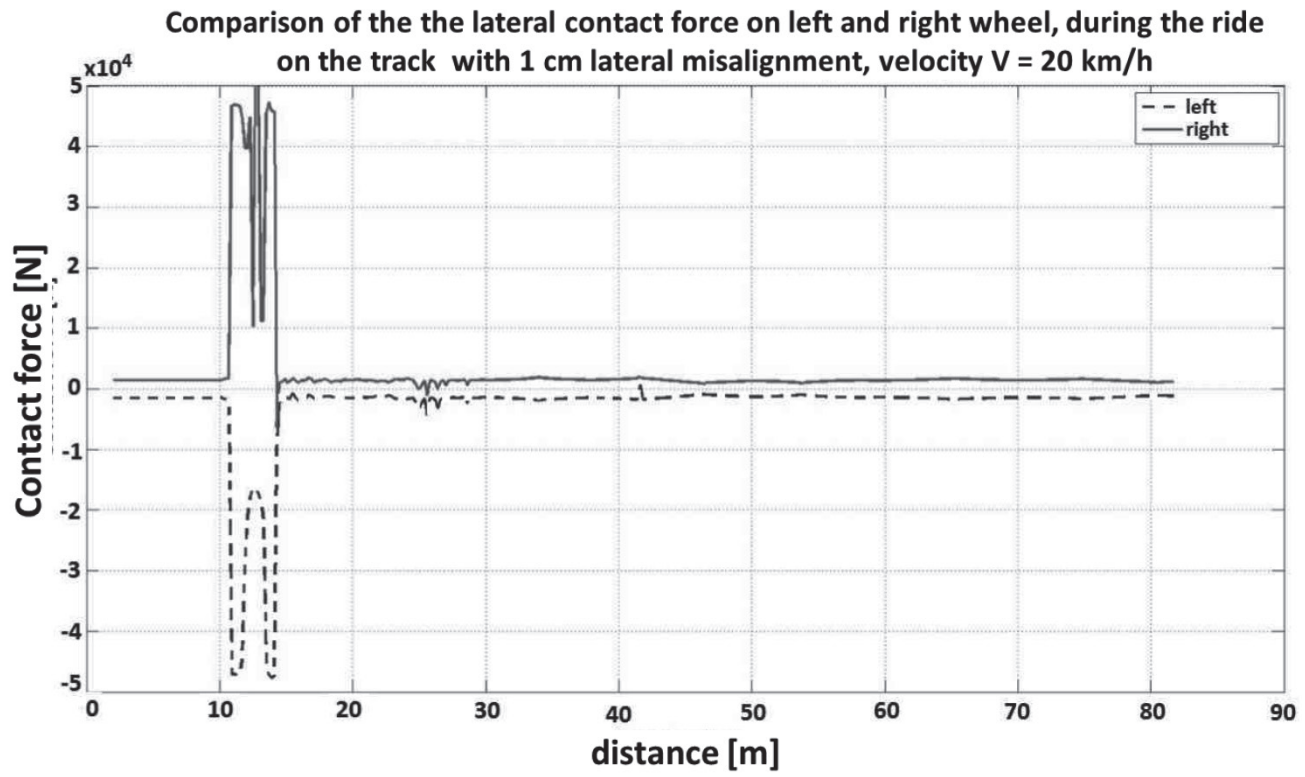

Fig. 12 Lateral contact forces on the left and right wheel during the ride on the on the track with $2 \mathrm{~cm}$ lateral misalignment; $20 \mathrm{~km} / \mathrm{h}$

mathematical model of contact what mainly expresses in formulas of the creepages. Various simulations were performed for real wheel and rail profiles and different track geometries. They revealed the characteristic features of bogie with independently rotating wheels, which are: no self-centring ability, easy radial positioning, long contact of the flange with the rail. The scenarios of the ride on the buckled track and track with lateral misalignment give an insight on how strong influence has the ride velocity and size of the irregularity on the bogie motion. The responses of the system are hardly predictable.

\section{Acknowledgement}

The work was done as a part of the research project WND-DEM-1-493/000, "Support for scientific research and development on a demonstration scale DEMONSTRATOR+".

\section{References}

[1] GOODALL, R. M., HONG, L.: Solid Axle and Independently Rotating Wheelsets - A Control Engineering Assessment of Stability, Vehicle System Dynamics, vol. 33, 2000, pp. 57-67.

[2] MIYAMOTO, M., SATO, T.: Study on the Stabilization of Railway Vehicles with Independently Rotating Wheels by Control of Steering on Wheelset (1 Axle trailer bogie), JSME, 10th Conf. Transportation 01-36, 2001, pp. 149-152.

[3] OBATA, R., TANIFUJI, K., SOMA, H., MASUDA, T.: Curving Performance of a Rail Vehicle with Independently Rotating Wheels by Torque Difference Control, Transaction of the Japan Society of Mechanical Engineers Series C, vol. 72, No. 716, 2006, pp. 1064 1070.

[4] MEI, T. X., GOODALL, R. M.: Practical Strategies for Controlling Railway Wheelsets Independently Rotating Wheels, $A S M E$, vol. 125, 2003, pp. 354-360.

[5] JAWAHAR, P. M., GUPTA, K. N.: Mathematical Modelling for Lateral Dynamic Simulation of a Railway Vehicle with Conventional and Unconventional Wheelset, Mathematical and Computer Modelling, vol. 14, 1990, pp. 989-994.

[6] DUKKIPATTI, R. V., OSMAN, M. O. M., NARAYANA SWAMY, S.: Independently Rotating Wheel Systems for Railway Vehicles - A State of the Art Review, Vehicle System Dynamics, vol. 21, 1989, pp. 297-330.

[7] FREDERICH, F.: Dynamics of a Bogie with Independent Wheels, Vehicle System Dynamics: Intern. J. of Vehicle Mechanics and Mobility, vol. 19, 1989, pp. 271-232.

[8] FREDERICH F.: A bogie concept for the 1990s, Railway Gazette International, vol. 9, 1988. pp. 583-585. 


\section{COMMNICOIIONS}

[6] CHO, Y., KWAK, J.: Development of a New Analytical Model for a Railway Vehicle Equipped with Independently Rotating Wheels, Intern. J. of Automotive Technology, vol. 13, No. 7, 2012, pp. 1047-1056.

[10] KUBA, T., LUGNER. P.: Dynamic Behaviour of Tramways with Different Kinds of Bogies, Vehicle System Dynamics: Intern. J. of Vehicle Mechanics and Mobility, vol. 50, 2012, pp. 277-289.

[11] CHUDZIKIEWICZ, A., SOWINSKA, M.: A Comparative Simulation Studies of a Conventional Bogie and Bogie with Independently Rotating Wheels (in Polish), Pojazdy Szynowe, vol. 2, 2014.

[12] CHUDZIKIEWICZ, A., SOWINSKA, M.: Low Floor Trams Running Gear - A Comparative Simulation Studies, 14th Mini Conference on Vehicle System Dynamics, Identification and Anomalies 2014, Book of Abstracts, p. 11.

[13] Safety of Railroad Passenger Vehicle Dynamics - Final Summary Report, U.S. Department of Transportation, Office of Research and Development, 2002. 